\title{
P 017 PATTERNS OF DIAGNOSES AMONGST CHILDREN AND YOUNG ADULTS WITH LIFE-LIMITING CONDITIONS; IMPLICATIONS FOR SERVICE PROVISION
}

Lorna Fraser, ${ }^{1}$ Victoria Lidstone, ${ }^{5}$ Michael Miller, ${ }^{4}$ Jan Aldridge, ${ }^{4}$ Paul Norman, ${ }^{3}$ Patricia McKinney, ${ }^{2}$ Roger Parslow ${ }^{2} .{ }^{1}$ Dept of Health Sciences, University of York, York, UK; ${ }^{2}$ Dept of Epidemiology, University of Leeds, Leeds, UK; ${ }^{3}$ School of Geography, University of Leeds, Leeds, UK; ${ }^{4}$ Martin House Children's Hospice, Boston Spa, UK; ${ }^{5}$ Cardiff and Vale UHB, Cardiff, UK

\subsection{6/bmjspcare-2014-000654.58}

Background The numbers of children and young people with Life-Limiting Conditions (LLC) are rising due in part to increased survival. Therefore the teenagers and young adults with LLC require transition to appropriate adult services but the models of care for these services need to be aware of the diagnostic and demographic makeup of this population.

Aims This study aimed to describe the patterns of diagnoses by age group in children and young adults with Life-Limiting Conditions.

Methods Individuals ( $0-40$ years) with LLCs were identified within an English Hospital Episode Statistics dataset by applying a customized coding framework of the ICD-10 disease codes. Prevalence per 10000 population was calculated by five year age groups for each diagnostic group, stratified by gender.

Results There is a U shaped prevalence with the highest overall prevalence in the under one age group (127 per 10000), decreasing until age $21-25$ years (21 per 10000$)$ before rising steeply to reach 55 per 10000 in the $36-40$ year age group. Prevalence is higher in males than females until the age group 21-25 years where females predominate and the gap widens to 61.8 per 10000 female (95\% CI 59.5-60.7) and 51.1 per 10000 male (95\% CI $49.0-50.1)$ by age $36-40$ years. Congenital Anomalies are the highest prevalence in children until age 16-20 years when oncology diagnoses become the most prevalent, rising steeply in early adulthood to 25 per 10000 by age 36-40 years. The second most prevalent diagnoses after age 25 years are neurology diagnoses in females and genitourinary diagnoses in males.

Conclusions Patients with oncology diagnoses usually have different needs from a palliative care service than patients with slowly degenerative diseases. The diagnostic and demographic breakdown of the population of teenagers and young adults with LLCs is important when planning future service provision. 